\title{
TRENDS IN MULTIDRUG-RESISTANT TUBERCULOSIS
}

DIAS-BAPTISTA I. M. F. (1), USÓ S. M. R. S. (1), MARCONDES-MACHADO J. (2)

(1) Lauro de Souza Lima Institute, Bauru, São Paulo State, Brazil; (2) Department of Tropical Diseases and Imaging Diagnosis, Botucatu School of Medicine, São Paulo State University, UNESP, Botucatu, São Paulo, Brazil.

ABSTRACT: Multidrug-resistant tuberculosis (MDR-TB) is an increasing global problem. The extent and burden of MDR-TB varies significantly from country to country and region to region. Globally, about three per cent of all newly diagnosed patients have MDR-TB and the proportion is higher in patients who had previously received anti-tuberculosis (anti-TB) treatment reflecting the failure of programs designed to ensure complete cure of patients with tuberculosis. The management of MDR-TB is a challenge that should be undertaken by experienced clinicians at centers equipped with reliable laboratory services and implementation of DOTS-Plus strategy.

KEY WORDS: Tuberculosis, MDR-TB, XDR-TB, DOTS, DOTS-Plus.

CONFLICTS OF INTEREST: There is no conflict.

\section{CORRESPONDENCE TO:}

IDA MARIA FOSCHIANI DIAS BAPTISTA, Instituto Lauro de Souza Lima, Rodovia Comandante João Ribeiro de Barros, Km 225, 17034-971, Bauru, SP, Brasil. Phone: +(55) 143103 5946. Email: ifoschiani@gmail.com. 


\section{INTRODUCTION}

Tuberculosis (TB) has a long history. It was present before the beginning of recorded history and has left its mark on human creativity, music, art, and literature. It has also influenced the advance of biomedical sciences and healthcare. Its causative agent, Mycobacterium tuberculosis, may have killed more persons than any other microbial pathogen (13).

Despite the recent progress of global control efforts, tuberculosis remains a major public-health burden in most developing countries. Current global estimates indicate that about a third of the world's population is infected with M. tuberculosis, 8.7 million individuals develop the disease annually, and, in 2003, almost 2 million deaths occurred (55).

At the second half of the XVII century, when the disease reached a high level of death rates in Europe, it became the main cause of death by the end of the XIX and beginning of the $\mathrm{XX}$ centuries; Robert Koch in 1882, identified the bacterium as the TB etiological agent. Thirty-nine years later, BCG vaccine was introduced for human use and became the most widely used prophylactic strategy to fight TB in the world. The introduction of antibiotics, such as streptomycin (1947), isoniazid (synthesized in 1912, but introduced 40 years later) and p-aminosalicylic acid, led to revolution in TB chemotherapy. Introduction of chemotherapy with additional new drugs and prophylactic measures resulted in drastic death reduction which was maintained for several decades $(16,35)$.

In the past few years, the standard chemotherapy scheme recommended by the World Health Organization (WHO) to control and/or eradicate TB worldwide has been based on a short-course therapy that combines the use of four anti-TB drugs. This strategy is currently known as DOTS (Directly Observed Treatment Strategy) and it is used to prevent development of drug-resistance. It relies on direct observation of patient compliance to ensure effective treatment $(11,43)$.

Although chemotherapy has been developed to combat TB, which has brought considerable reduction in incidence in developed nations, historical data calculated by WHO indicates that there have not been great effects on the global problem since the time of Koch (4). In 1993, WHO declared TB a global public health emergency. This has been attributed to several factors, such as the HIVIAIDS pandemic (in the beginning of the 1980s); changes in social structure; the increase in immigrants from high prevalence nations to developed ones; the aging of the world population; the 
active transmission among environments of human accumulation (such as prisons, hospitals, and homeless shelters); the degradation of health care systems; and the increase in drug-resistance (19).

Although TB became a reemerging disease to European and North-American nations, TB is not an emergent or reemerging public health problem in developing countries such as Brazil, but rather a long-lasting one (38). In nations such as India, China, Indonesia, Pakistan, Nigeria, Philippine, South Africa, Ethiopia, Vietnam, Russian Federation, Democratic Republic of Congo, Brazil, United Republic of Tanzania, Kenya, Thailand, Myanmar, Afghanistan, Uganda, Peru, Zimbabwe, and Cambodia, it is estimated an occurrence of up to $80 \%$ of the world TB cases (16).

Progression of TB infection is fundamentally regulated by the host immune system integrity. The microbe may be immediately eliminated or remain latent, in this case, there will be development of active disease. There is a great variability in the infection rates among people exposed to different infection sources, and among infected ones, approximately $90 \%$ will never develop the disease. There are also differences in the capacity to transmit the infection among patients due to exhaled bacterial charge variability. Experimental evidence also suggests that the observed variation in transmission potential might be attributed to pathogenic features. Mycobacterium tuberculosis can have virulence variations among different strains; the most virulent ones present higher pathogenicity or capacity to develop active disease. It has been shown that untreated TB patients have mortality rates ranging from $40 \%$ to $60 \%$. Although genes will not influence the risk of infection upon exposure, they might determine the risk of disease development and its course (12, 16).

Mycobacteria show a high degree of intrinsic resistance to most antibiotics and chemotherapeutic agents due to the low permeability of their cell wall. Mycobacterium tuberculosis mutants resistant to any single drug are naturally present in any large bacterial population, irrespective of exposure to drugs. The frequency of mutants resistant to rifampicin and isoniazid, the two main antimycobacterial drugs currently in use, is relatively high and, therefore, the large extracellular population of actively metabolizing and rapidly growing tubercle bacilli in cavitary lesions will contain organisms which are resistant to a single drug. Consequently, monotherapy or improperly administered two-drug therapies will select 
drug-resistant mutants that may lead to drug-resistance in the entire bacterial population $(12,16)$.

\section{EPIDEMIOLOGY OF MULTIDRUG-RESISTANT TUBERCULOSIS: GLOBAL INCIDENCE AND PREVALENCE}

Multidrug-resistant tuberculosis (MDR-TB) presents concerning challenge to TB control in several settings, but the global burden is largely unknown. MDR-TB requires longer duration of treatment (up to 2 years) to achieve cure, in comparison with 6-month treatment for drug-susceptible TB, lower cure rates and even higher default rates. Infection control of MDR-TB is more difficult to implement in hospitals due to the long time taken for drug susceptibility testing (DST) results become available, and consequently the delayed start of the adequate treatment, as well as impaired response to second-line anti-TB treatment. The cost of drugs to treat a MDR-TB case can be up to 100 times more expensive than the cost of treating a drug-susceptible TB case (27).

In particular, MDR-TB, defined as TB showing resistance to at least isoniazid and rifampicin, has become a major concern, at least in some parts of the world. In this context, resistance to anti-TB drugs is usually described in terms of "resistance among new cases" and "resistance among previously treated patients" $(43,20)$. The term "susceptible strains" refers to those strains that have not been exposed to the first-line anti-TB drugs and respond to these drugs in a uniform manner. The term "resistant strains" refers to those strains that differ from the sensitive strains in their capacity to grow in the presence of a higher concentration of a drug $(42,43)$. MDRTB has been documented in nearly 90 countries and regions worldwide (54): The number of incident MDR-TB cases estimated to have occurred globally in 2004 is, therefore, 424,203 , which accounts for $4.3 \%$ of the $9,880,382$ new and previously treated cases notified in the 184 countries (57). Treatment for MDR-TB patients requires the use of second-line drugs for additional 24 months. These drugs are more costly, toxic, and less effective than first-line drugs used for routine treatment of TB $(24,36,40)$. Resistance to TB drugs results primarily from nonadherence by patients, incorrect drug prescription by providers, poor-quality drugs, or irregular supply of drugs (34).

Recent documentation of the emergence of strains with extensive drug-resistance (XDR-TB), i.e. multidrug-resistant strains with resistance to at least three of the six 
main classes of second-line drugs, is extremely worrisome. As a result, standardized drug susceptibility test for second-line drugs, mainly in cases of MDR-TB, will be required to further establish the magnitude of XDR-TB. All means should be urgently put in place to control these deadly strains $(2,5,21)$.

The global distribution of TB cases is skewed heavily toward low-income and emerging economies. The highest prevalence of cases is in Asia, where China, India, Bangladesh, Indonesia and Pakistan collectively make up over $50 \%$ of the global burden. Africa and more specifically the sub-Saharan Africa have the highest incidence rate of TB, with approximately 83 and 290 per 100,000, respectively. TB cases occur predominantly (approximately 6 million out of 8 million) in the economically most productive 15- to 49-year-old age group (14). Our understanding of TB epidemiology and the efficacy of control activities have been complicated by the emergence of drug-resistant bacilli and by the synergism of TB with HIV coinfection (30).

In 1994, WHO, the International Union Against Tuberculosis and Lung Disease, and other partners launched the Global Project on Anti-tuberculosis Drug-resistance Surveillance. The aim of this project is to determine the prevalence, patterns, and trends of anti-TB drugs resistance around the world, ultimately to improve the performance of national tuberculosis control programs through policy recommendations on patient management. The project measures in vitro drug susceptibility to four of the six first-line anti-TB drugs, i.e. isoniazid, rifampicin, streptomycin and ethambutol $(2,7,53)$.

In its first two reports, the project has provided a better understanding of the magnitude and distribution of anti-TB drugs resistance and has led to policy development for the treatment of $\operatorname{MDR}-\operatorname{TB}(2,18,33,50,51)$.

In the 80s, in the United States, Europe and Latin America, highly resistant strains of tuberculosis have caused explosive institutional outbreaks (in hospitals, prisons and homeless shelters) with high case fatality rates among immunosuppressed people and high rates of transmission to other patients and to caregivers and their families $(3,39,48)$.

Currently, MDR-TB presents a high incidence, in an increasing order, in Latvia, India, Estonia, Dominican Republic and Argentina, and low incidence in most occidental European and African countries and the United States $(16,19)$. 
The prevalence of MDR-TB was exceptionally high in almost all countries from the former Soviet Union that were surveyed, including Estonia, Kazakhstan, Latvia, Lithuania, the Russian Federation, and Uzbekistan. High prevalence rates of MDRTB were also found among new cases in China (Henan and Liaoning provinces), Ecuador and Israel. Central Europe and Africa, in contrast, reported the lowest levels of drug-resistance $(43,54)$. Recent report from 184 countries suggests that an estimated 458,000 new cases of MDR-TB occurred worldwide in 2003, with 276,000 of those cases $(60 \%)$ reported from high-burden countries, from which China and India constituted $3.2 \%$ of all new TB cases $(43,57)$. Nevertheless, it should be remembered that increases in the prevalence of resistance can be caused by poor or worsening TB control, immigration of patients from areas of higher resistance, outbreaks of drug-resistant disease, and variations in surveillance methodologies $(42,43)$.

Factors related to incomplete and inadequate treatment are implicated in the causation of MDR-TB. Errors in TB management such as the use of single drug to treat TB, the addition of a single drug to a failing regimen, the failure to identify preexisting resistance, the initiation of an inadequate primary regimen, the failure to identify and address nonadherence to treatment, inappropriate isoniazid preventive therapy, and variations in the bioavailability of anti-TB drugs predispose the patient to the development of MDR-TB. Nonadherence to prescribed treatment is often underestimated by the physician and is difficult to predict. Besides, certain factors such as psychiatric illness, alcoholism, drug addiction, and homelessness are known as cause of nonadherence to treatment $(41,42)$.

Current evidence suggests that HIV infection per se does not appear to be a predisposing factor for the development of MDR-TB. Some studies have found that MDR-TB is not more common among people infected with HIV. However, increased immunological susceptibility, overcrowding, exposure to patients with MDR-TB during hospital visits, and malabsorption of anti-TB drugs resulting in suboptimal therapeutic blood levels, despite strict adherence to the treatment regimen, potentially increase the chances of MDR-TB occurring in persons with HIVIAIDS. The DOTS, which has been endorsed by WHO as the only effective way to control TB has, to some extent, addressed these problems $(41,43,45)$. 


\section{Mycobacterium tuberculosis GENOME AND VIRULENCE}

Spontaneous chromosomally borne mutations occurring in $M$. tuberculosis at a predictable rate are thought to confer resistance to anti-TB drugs. A characteristic feature of these mutations is that they are unlinked. A TB cavity usually contains $10^{7}$ to $10^{9}$ bacilli. If mutations causing resistance to isoniazid occur in about 1 in $10^{6}$ replications of bacteria, and the mutations causing resistance to rifampicin occur in about 1 in $10^{8}$ replications, the probability of spontaneous mutations causing resistance to both isoniazid and rifampicin would be $10^{6} \times 10^{8}=1$ in $10^{14}$ replications. Given that this number of bacilli cannot be found even in patients with extensive cavitary pulmonary TB, the chance of development of spontaneous dual resistance to rifampicin and isoniazid will be practically remote. Various perturbations in the individual drug target genes are responsible for the genesis of anti-TB drugs resistance. Rifampicin resistance has been shown to be caused by a change in the $\beta$-subunit of RNA polymerase, which is encoded by the rpo $\beta$ gene. More than $95 \%$ of rifampicin-resistant strains are associated with mutations within an 81-base pair region of the rpo $\beta$ gene, which is termed rifampicin resistance determinant region. On the contrary, resistance to isoniazid is more complicated, as mutations in several genes can lead to drug-resistance. While certain mutations are widely present, pointing to the magnitude of the polymorphisms at these loci, others are not common, suggesting diversity in the multidrug-resistant $M$. tuberculosis strains that are prevalent in the given region. Furthermore, rifampicin resistance has been considered to be a surrogate marker for checking multidrug-resistance in clinical isolates of $M$. tuberculosis since rifampicin resistance is often accompanied by resistance to isoniazid $(43,47)$.

Substantial progress has been made in the understanding of the molecular epidemiology of tubercle bacilli with the availability of genome sequence data in the public domain (43). The complete genome sequencing of the best characterized $M$. tuberculosis strain, H37Rv, shows a circular chromosome with 4,411,529 base pairs with a $65.6 \% \mathrm{G}+\mathrm{C}$ content. Although $M$. tuberculosis genome is smaller than that of Escherichia coli, it is very versatile, coding for most of the typical bacterial anabolic and catabolic pathways and amino acid synthesis/degradation. With approximately 4,000 genes, mostly coding for enzymes involved in lipolysis (for bacterial survival inside its host) and lipogenesis (for cellular envelope synthesis), it has around 250 enzymes involved in fatty acid metabolism. The $M$. tuberculosis genome is rich in 
repetitive DNA, especially insertion sequences, inserted in intergenic or non-coding regions, frequently close to tRNA genes (16).

Phylogenomic analysis suggests that the "ancient strains" of $M$. tuberculosis may have undergone adaptive evolution as a result of selection at many loci. Extrapolating data on the virulence and survival capability of isoniazid-resistant strains to multidrug-resistant strains of M. tuberculosis, it has been assumed that multidrug-resistant isolates have lower virulence and survival capability. It has been observed that emergence of multidrug-resistance may result in the organism becoming unusually fit to survive because this perception is based on the observation that mutations that confer resistance often alter important gene products (6). This is exemplified by a genotype, which was first described in 1995, known as the W-Beijing family. Published reports $(9,25)$ have suggested that W-Beijing genotype is highly prevalent in some regions of Asia and Eastern Europe such as Estonia, Azerbaijan and Russia. The strains belonging to the W-Beijing family have been shown to exhibit a constant spoligotype and high degrees of similarity among IS6110 restriction fragment length polymorphism (RFLP), polymorphic GC-rich sequence RFLP, and variable numbers of tandem repeats profiles. W-Beijing genotype is well known for its rapidity of spread and tenacity, and notably for its strong association with multidrug-resistance. Given that the Beijing strain has already made its appearance in India, where $20 \%$ of the TB patients in the world are located, the consequences can be disastrous (44). However, caution must be exercised while interpreting these data as these observations need to be validated in multiple settings before definitely linking the clone to the given host population $(1,43)$.

\section{WORLDWIDE EMERGENCE OF EXTENSIVELY DRUG-RESISTANT TUBERCULOSIS}

During the 1990s, MDR-TB, defined as resistance to at least isoniazid and rifampin, emerged as a threat to TB control, both in the United States and worldwide. MDRTB treatment requires the use of second-line drugs (SLDs) that are less effective, more toxic, and costlier than first-line isoniazid and rifampin-based regimens. In 2000, the Stop TB Partnership's Green Light Committee was created to increase access to SLDs worldwide while ensuring their proper use to prevent increased drugresistance. While assisting MDR-TB treatment programs worldwide, the committee encountered reports of multiple cases of TB with resistance to virtually all SLDs. To 
assess the frequency and distribution of extensively drug-resistant (XDR) TB cases, Centers for Disease Control (CDC) and WHO surveyed an international network of TB laboratories. The results of that survey determined that, during 2000-2004, of 17,690 TB isolates, $20 \%$ were MDR and $2 \%$ were XDR. In addition, population-based data on drug susceptibility of TB isolates were obtained from the United States (for 1993-2004), Latvia (for 2000-2002), and South Korea (for 2004), where 4\%, 19\%, and $15 \%$ of MDR-TB cases, respectively, were XDR. XDR-TB has emerged worldwide as a threat to public health and TB control, raising concerns of a virtually untreatable future TB epidemic (5).

New anti-TB drugs regimens, better diagnostic tests, and international standards for SLD-susceptibility testing are needed for effective detection and treatment of drugresistant TB. From November 2004 to November 2005, CDC and WHO surveyed the WHO/International Union Against Tuberculosis and Lung Disease Global Supranational TB Reference Laboratory (SRL) Network. The SRL Network consists of 25 reference laboratories on six continents that collaborate with National Reference Laboratories (NRLs) to increase culture and drug-susceptibility testing capacity and provide quality control for global surveys to assess anti-TB drugs resistance. Using a standardized reporting form, CDC and WHO requested anonymous, individual-level data on all isolates tested for susceptibility to at least three SLD classes during 2000-2004 and maintained it in a computerized registry. SRLs receive varying proportions of isolates from countries for surveillance, diagnosis, and quality assurance. Thus, SLD-susceptibility data from SRLs are based on a convenience sample and are not population-based. The study sample for the SRL analysis consisted of 17,690 isolates from the period 2000-2004 that were tested for susceptibility to at least three of the six SLD classes. Of these, 11,939 were from South Korea, of which 1,298 (11\%) were MDR. From the other SRLs, $2,222(39 \%)$ of 5,751 isolates were MDR. Of the 3,520 MDR isolates, $347(10 \%)$ were XDR, including 200 (15\%) of 1,298 from South Korea and $147(7 \%)$ of 2,222 from other SRLs. The drug-susceptibility test results were tabulated by year and geographic region (on the basis of the country of origin of the isolates). XDR-TB was identified in all regions but it was most common in South Korea ( $n=200 ; 15 \%$ of all MDR-TB isolates) and countries of Eastern Europe/Western Asia ( $n=55 ; 14 \%$ of all MDR-TB isolates). The total number and proportion of XDR-TB isolates observed worldwide (excluding South Korea) increased from 14 (5\% of MDR-TB isolates) in 
2000 to 34 (7\% of MDR-TB isolates) in 2004. Year-specific proportions were stratified by geographic region. Increasing proportions of XDR-TB were found among isolates from countries of Eastern Europe/Western Asia ( $n=5$ [9\%] in 2000; $n=11$ [17\%] in 2003 ) and the group of industrialized nations ( $n=3$ [3\%] in 2000; $n=25$ [11\%] in 2004) (5). Among 605 MDR-TB patients in Latvia who initiated therapy during 2000-2002, $115(19 \%)$ had XDR-TB. The proportion with XDR-TB increased from 30 (15\%) of 204 in 2000, to $46(21 \%)$ of 215 in 2001, and to 39 (21\%) of 186 in 2002. Patients with XDR were $54 \%$ more likely to die or have treatment failure $(5,27)$.

The numerous outbreaks of MDR-TB during the early 1990s were harbingers of a global epidemic. During 1994-2002, the WHO Global Project on Anti-TB drugs Resistance Surveillance coordinated data collection on more than 250,000 patients from 109 countries (or regions within large countries), representing $42 \%$ of the world's population. On this basis, WHO estimated the annual burden of MDR-TB to be approximately $300,000-600,000$ cases and the prevalence of MDR-TB to be threefold higher than the annual incidence, primarily in low- and middle-income countries. The emergence of XDR-TB, coupled with increased use of SLDs, suggests that urgent measures are needed to establish population-based surveillance for SLD resistance and to plan public health policies. However, existing tests for susceptibility to SLDs are less reproducible than tests for susceptibility to isoniazid and rifampin, and better methods are needed. The findings in WHO's report are subject to at least two limitations. First, SLD testing methods and results have varied because of the lack of international standards and the limited reproducibility of drug-susceptibility test for certain drugs. For this survey, testing methods and specific drugs tested varied according to the SRL. Second, the SRL data were drawn from a convenience sample of isolates and may reflect a referral bias; SRLs are likely to receive isolates from retreatment cases, treatment failures, or other complex TB cases. In spite of that, these data indicate that XDR-TB is geographically widespread. The populationbased data from South Korea, the United States, and Latvia provide a more representative picture of XDR-TB on a population level in three disparate regions of the world and confirm that XDR-TB has emerged in multiple settings, including the United States where TB control has been effective for many years (56).

In face of these limitations, XDR-TB poses a serious and emerging public health threat. Population-based surveillance data are needed to describe the magnitude and trends of XDR-TB worldwide. Activities to detect drug-resistant TB accurately and 
rapidly and treat it effectively should be expanded, including development of international standards for SLD-susceptibility test, new anti-TB drugs regimens, and improved diagnostic tests. Such measures are crucial if future generations are to be protected from XDR-TB $(18,19)$.

\section{DOTS STRATEGY}

In 1994, the internationally recommended control strategy, later named DOTS, was launched. It stands for Directly Observed Treatment Short-course, and its key components include (29):

- $\quad$ Government commitment;

- $\quad$ Case detection by predominantly passive case finding;

- $\quad$ Standardized short-course chemotherapy for, at least, all confirmed sputum Acid-Fast Bacilli (AFB) smear-positive cases, provided under proper case management conditions;

- $\quad$ A system of regular drug supply; and

- A monitoring system for program supervision and evaluation.

A total of 183 countries and territories were implementing the DOTS strategy in 2004. By the end of $2004,83 \%$ of the world's population lived in countries covered by DOTS. DOTS programs notified 4.4 million new and relapse TB cases in 2004, of which 2.1 million were new AFB smear-positive. In total, 21.5 million TB patients and 10.7 million AFB smear-negative patients were treated in DOTS programs during the period of 1995-2004 $(43,56)$.

There is, however, much variation between regions. Treatment success exceeded the $85 \%$ target in the Western Pacific region, largely because China reported a $93 \%$ success rate. Clearly, the biggest failure of DOTS has been in Africa, where rates of TB continue to rise, seeming unabated. In 2002, the African region showed less than $75 \%$ cure rates, and death rates were as high as $8 \%$ in patients co-infected with $M$. tuberculosis and HIV. Eastern Europe, another region plagued by poor health systems and an expanding HIV epidemic, witnessed continued increases in TB incidence rates throughout the 1990s, though the increase now seems to have peaked. Increases in incidence rates of disease are also noted in Central Asian countries, though the death rate in DOTS recipients remains stable at $5 \%$. Both Eastern Europe and Central Asia are also hotspots of MDR-TB $(15,20,56)$. 
Based upon DOTS, DOTS-Plus is a comprehensive management strategy under development and testing that includes the five tenets of the DOTS strategy. DOTSPlus takes into account specific issues (such as the use of second-line anti-TB drugs) that need to be addressed in areas where there is high prevalence of MDR-TB. These drugs should be stored and dispensed at specialized health centers with appropriate facilities and well trained staff. The regimen includes two or more second-line TB drugs to which the isolate is susceptible, including one drug given parenterally for six months or more. The total duration of treatment is directly observed for 18-24 months $(29,52)$.

A retrospective observational study of a cross-sectional sample of sputum smearpositive TB patients used to determine the association between DOTS end-oftreatment outcomes, subsequent rediagnosis of active TB, death, and other predictors including drug-resistance was developed in Karakalpakstan Republic, Uzbekistan, with a high TB burden (total case notifications 462/100,000/year) and high drug-resistance (13\% among new and 40\% among previously treated patients) (10). The DOTS strategy was implemented progressively in this region starting in 1998, in line with recommendations from WHO and the International Union Against Tuberculosis and Lung Disease (IUATLD), replacing the existing Soviet-style system of TB diagnosis and treatment. In 2003, it covered the total population of approximately 1.5 million (8).

This study has demonstrated extremely high mortality and high rates of disease recurrence after "successful" treatment among TB patients treated with standardized short-course chemotherapy under a routine DOTS program. Despite the lack of data differentiating relapse from reinfection, high recurrence in such settings of drugresistance suggests that DOTS programs will have limited impact in terms of reducing TB incidence. Overall, $15 \%$ of patients died per year after diagnosis, and $36 \%$ of successfully treated patients were rediagnosed with active TB. Both MDR-TB and drug polyresistance contributed to high rates of recurrence and mortality after successful treatment. Among those infected with MDR M. tuberculosis, the rate of recurrent disease after successful treatment was $63 \%$, with the majority positive by sputum smear. These data suggest that, at least in this setting, and potentially in other settings with similar drug-resistance profiles, DOTS programs are not sufficient to cure enough number of individuals or for TB control. The expansion of DOTS-Plus 
programs for the specific treatment of drug-resistant TB is therefore urgently needed, particularly in resource-poor settings $(8,10)$.

DOTS-Plus is not intended to be a universal strategy and is not required in all settings and should be implemented in selected areas with moderate to high levels of MDR-TB in order to combat an emerging epidemic. DOTS-Plus is already being implemented in Bolivia, Costa Rica, Estonia, Haiti, Karakalpakstan (Uzbekistan), Latvia, Malawi, Mexico, Peru, Philippines and the Russian Federation (Arkhangelsk, Ivanono, Tomsk and Orel Oblasts) $(22,29,52,56)$.

The results from the retrospective study designed to assess treatment outcomes for the first full cohort of MDR-TB patients $(n=204)$, who were treated under the Latvian DOTS-Plus strategy following WHO guidelines, have been encouraging; $66 \%$ patients were cured or completed therapy, $7 \%$ died, $13 \%$ defaulted, and $14 \%$ did not respond to treatment. Data on adverse drug reactions (ADRs) collected from five DOTS-Plus sites in Estonia, Latvia, Peru (Lima), the Philippines (Manila), and the Russian Federation (Tomsk Oblast) showed that, among 818 patients enrolled for MDR-TB treatment, only $2 \%$ of patients stopped treatment and $30 \%$ required removal of the suspected drugs from the regimen and use of alternative drugs due to ADRs. These findings indicate that ADRs are manageable in the treatment of MDR-TB even in resource-limited settings provided that standardized management strategies are followed (43).

The efficacy of strategies such as DOTS-Plus in the management of MDR-TB patients under program conditions should be tested in well-designed operational clinical field trials strictly following standardized definitions and nomenclature. Ethnic variations in the pharmacokinetics of anti-TB drugs and the utility of therapeutic drug monitoring in the management of patients with MDR-TB need further study. The field testing of newer anti-TB drugs that are on the horizon and generating evidence, regarding their efficacy, deserves special mention as there is renewed hope of shortening the treatment duration $(31,40)$.

\section{COST-EFFECTIVENESS OF TREATING MULTIDRUG-RESISTANT TUBERCULOSIS}

According to $\mathrm{WHO}, \mathrm{TB}$ is estimated to take an annual economic toll equivalent to US\$12 billion from the incomes of poor communities. Studies have suggest that, on average, 3-4 months of work time are lost due to TB, resulting in mean lost potential 
earnings of $20 \%-30 \%$ of the annual household income. For these families, a further income loss of $\sim 15$ years due to premature death caused by TB is estimated by WHO $(28,52)$.

In countries with unstable TB control programs, treatment regimens should use rifampicin only in the form of combined tablets of proven bioavailability to avoid monotherapy and to control the sale of anti-TB drugs on the private market (17). The provision of four-first-line-drug fixed-dose combination tablets through the global drug facility for < US\$10 per treatment is a promising approach to the treatment of nonresistant TB to prevent the further increase and spread of drug-resistance (23).

The treatment of MDR-TB patients is up to 100 times more expensive than that of fully sensitive patients. The cost-effectiveness of Directly Observed Treatment (DOT) for MDR-TB was demonstrated in an assessment between the USA and South Africa. Cost savings of US\$1,788 and US\$2,215 per patient treated with DOT were found, compared to conventional treatment. Although conventional treatment was approximately twice the cost of DOT in South Africa (1.5 times with second-line drugs), a saving of $8 \%$ was reported in the USA (49).

Laing and McGoldrick found dramatic variations in drug price between different countries. However, they came to the conclusion that the "free market" seems to be functioning for first-line drugs. For second-line drugs, they pointed out that the "free market" was not functioning efficiently and the true international price was not clear. They reasoned that this was due to the limited number of suppliers and the lack of large-scale tenders. With an increase in DOTS-Plus projects, they expected a decrease in prices (26).

In order to reduce the immensely high cost and foster the rational use of and access to second-line drugs, WHO has established a working group for the DOTS-Plus approach. Reduced price second-line drugs should only be given to projects adhering to international recommendations of a multi-institutional body known as the "Green Light Committee". Thus, countries with budgets that include the purchase of second-line drugs (e.g. Estonia) could save up to $57.5 \%$ of their overall budget for TB control (23).

The treatment and management of cases in resource settings require a sustainable and functioning national TB program, drug availability at a reasonable cost via the Global TB Alliance and some support for drug-resistance monitoring either within the country or provided outside the country via a partnership with a resource-rich 
country. This strategy has been tested in settings with a moderate MDR-TB problem, but with a good TB program, wide DOT provision and a good infrastructure for monitoring and delivery of treatment (32).

In Peru for example, 298 patients were treated for MDR-TB with a fixed regimen of kanamycin for 3 months, and pyrazinamide, ethambutol, ethionamide and ciprofloxacin for 18 months (46). Twelve per cent died, 48\% were cured, 12\% defaulted and $28 \%$ did not respond. The total cost was US\$600,000, which was $8 \%$ of the cost of the whole national program. The cost per patient completing treatment was US\$2,381 and the cost per Death-Adjusted Life Year (DALY) was US\$211. Peru is a middle-income country, with a strong TB program and little HIV at present. Such results and costs may only be applicable if these conditions are met. Where there is a poor TB control program, even such modest results may not be achieved $(32,37)$. In other settings, the attractiveness of strategies using second-line drugs will depend on TB incidence, MDR burden, and the available budget. However, treatment modified by drug susceptibility tests may improve the outcome in such DOTS programs, provided that there is drug availability and continuity at affordable prices. WHO is carefully vetting DOTS-Plus applications and monitoring them where they are implemented (32).

\section{CONCLUSION}

Because of that, despite the availability of effective chemotherapy and the moderately protective vaccine, new anti-TB agents are urgently needed to decrease the global incidence of TB. The resumption of TB, mainly caused by the emergence of multidrug-resistant (MDR) and extensively drug-resistant (XDR) strains and HIV epidemics, led to an increased need to understand the molecular mechanisms of drug action and drug-resistance, which should provide significant insight into the development of newer compounds. The latter should be effective to combat both drug susceptible and MDR/XDR-TB (35). 


\section{REFERENCES}

1 AHMED N., HASNAIN SE. Genomics of Mycobacterium tuberculosis: old threats \& new trends. Indian J. Med. Res., 2004, 120, 207-12.

2 AZIZ MA., WRIGHT A., LASZLO A., DE MUYNCK A., PORTAELS F., VAN DEUN A., WELLS C., NUNN P., BLANC L., RAVIGLIONE M. Epidemiology of antituberculosis drug-resistance (the global project on anti-tuberculosis drugresistance surveillance): an updated analysis. Lancet, 2006, 16, 2142-54.

3 BECK-SAGUE C., DOOLEY SW., HUTTON MD., OTTEN J., BREEDEN A., CRAWFORD JT., PITCHENIK AE., WOODLEY C., CAUTHEN G., JARVIS WR. Hospital outbreak of multidrug-resistant Mycobacterium tuberculosis infections. Factors in transmission to staff and HIV-infected patients. J. Am. Med. Assoc., 1992, 268, 1280-6.

4 BLOOM BR., MURRAY CJ. Tuberculosis: commentary on a reemergent killer. Science, 1992, 257, 1055-64.

5 CENTERS FOR DISEASE CONTROL AND PREVENTION. Emergence of Mycobacterium tuberculosis with extensive resistance to second-line drugs worldwide, 2000-2004. Morb. Mortal. Wkly. Rep., 2006, 55, 301-5.

6 COHEN T., MURRAY M. Modeling epidemics of multidrug-resistant M. tuberculosis of heterogeneous fitness. Nat. Med., 2004, 10, 1117-21.

7 COHN DL., BUSTREO F., RAVIGLIONE MC. Drug-resistant tuberculosis: review of the worldwide situation and the WHO/IUATLD global surveillance project. Clin. Infect. Dis., 1997, 24, S121-S130.

8 COX HS., KEBEDE Y., ALLAMURATOVA S., ISMAILOV G., DAVLETMURATOVA Z., BYRNES G., STONE C., NIEMANN S., RÜSCH-GERDES S., BLOK L., DOSHETOV D. Tuberculosis recurrence and mortality after successful treatment: impact of drug-resistance. Plos Med., 2006, 3, e384.

9 COX HS., KUBICA T., DOSHETOV D., KEBEDE Y., RÜSCH-GERDESS S., NIEMANN S. The Beijing genotype and drug resistant tuberculosis in the Aral Sea region of Central Asia. Respir. Res., 2005, 6, 134.

10 COX HS., OROZCO JD., MALE R., RÜSCH-GERDES S., FALZON D., SMALL I., DOSHETOV D., KEBEDE Y., AZIZ M. Multidrug-resistant tuberculosis in Central Asia. Emerg. Infect. Dis., 2004, 10, 865-72. 
11 DAM T., ISA M., BOSE M. Drug-sensitivity profile of clinical Mycobacterium tuberculosis isolates - a retrospective study from a Chest-Disease Institute in India. J. Med. Microbiol., 2005, 54, 269-71.

12 DANIEL TM. Captain of death: the story of tuberculosis. New York: University of Rochester Press, 1997.

13 DANIEL TM. The history of tuberculosis. Respir. Med., 2006, 100, 1862-70.

14 DYE C., SCHEELE S., DOLIN P., PATHANIA V., RAVIGLIONE MC. Global burden of tuberculosis: estimated incidence, prevalence and mortality by country. $J$. Am. Med. Assoc., 1999, 282, 677-86.

15 DYE C., WATT CJ., BLEED DM., HOSSEINI S., RAVIGLIONE MC. Evolution of tuberculosis control and prospects for reducing tuberculosis incidence, prevalence and deaths globally. J. Am. Med. Assoc., 2005, 293, 2767-75.

16 DUCATI RG., RUFFINO-NETO A., BASSO LA., SANTOS DS. The resumption of consumption - A review on tuberculosis. Mem. Inst. Oswaldo Cruz, 2006, 101, 697714.

17 ENARSON DA., BILLO NE. Critical evaluation of the Global DOTS Expansion Plan. Bull. World Health Organ., 2007, 85, 395-403.

18 ESPINAL MA., LAZLO A., SIMONSEN L., BOULAHBOL F., KIM SJ., RENIERO A., HOFFNER S., RIEDER HL., BINKIN N., DYE C., WILLIAMS R., RAVIGLIONE MC. Global trends in resistance to antituberculosis drugs. World Health Organization/International Union Against Tuberculosis and Lung Disease Working Group on Anti-Tuberculosis Drug-resistance Surveillance. N. Engl. J. Med., 2001, 344, 1294-303.

19 FATKENHEUER G., TAELMAN H., LEPAGE P., SCHWENK A., WENZEL R. The return of tuberculosis. Diag. Microbiol. Infect. Dis., 1999, 34, 139-46.

20 FRIEDEN TR., MUNSIFF SS. The DOTS strategy for controlling the global tuberculosis epidemic. Clin. Chest. Med., 2005, 26, 197-205.

21 GANDHI NR., MOLL A., STURM AW., PAWINSKI R., GOVENDER T., LALLOO U., ZELLER K., ANDREWS J., FRIEDLAND G. Extensively drug-resistant tuberculosis as a cause of death in patients co-infected with tuberculosis and HIV in a rural area of South Africa. Lancet, 2006, 368, 1575-80. 
22 GUPTA R., CEGIELSKI JP., ESPINAL MA., HENKENS M., KIM JY., LAMBREGTS-VAN WEEZENBEEK CS., LEE JW., RAVIGLIONE MC., SUAREZ PG., VARAINE F. Increasing transparency in partnerships for health: introducing the Green Light Committee. Trop. Med. Int. Health, 2002, 7, 970-76.

23 GUPTA R., RAVIGLIONE MC., ESPINAL MA. Should tuberculosis programmes invest in second-line treatments for multidrug-resistant tuberculosis (MDR-TB)? Int. J. Tuberc. Lung Dis., 2001, 5, 1078-79.

24 ISEMAN MD. Treatment of multidrug-resistant tuberculosis. N. Engl. J. Med., 1993, 329, 784-91.

25 KUBICA T., AGZAMOVA R., WRIGTH A., AZIZ MA., RAKISHEV G., BISMILDA V., RICHTER E., RÜSCH-GERDES S., NIEMANN S. The Beijing genotype is a major cause of drug-resistant tuberculosis in Kazakhstan. Int. J. Tuberc. Lung Dis. 2005,9,646-53.

26 LAING RO., MCGOLDRICK KM. Tuberculosis drug issues: prices, fixed-dose combination products and second-line drugs. Int. J. Tuberc. Lung Dis., 2000, 4, S194-207.

27 LEIMANE V., LEIMANS J. Tuberculosis control in Latvia: integrated DOTS and DOTS-Plus programmes. Eurosurveillance, 2006, 11, 1-3.

28 LODDENKEMPER R., SAGEBIEL D., BRENDEL A. Strategies against multidrugresistant tuberculosis. Eur. Respir. J., 2002, 20, S66-S77.

29 MARTIN A., PORTAELS F. Drug-resistance and drug-resistance detection. In: PALOMINO JC., LEÃO SC., RITACO V. Eds. Tuberculosis 2007: from basic science to patient care. 2007. Available from: www.TuberculosisTextbook.com.

30 MATHEMA B., KUREPINA NE., BIFANI PJ., KREISWIRTH BN. Molecular epidemiology of tuberculosis: current insights. Clin. Microbiol. Rev., 2006, 19, 65885.

31 NATHANSON E., WEEZENBEEK CL., RICH ML., GUPTA R., BAYONA J., BLONDAL K., CAMINERO JA., CEGIELSKI JP., DANILOVITS MAE., HOLLO V., JARAMILLO E., LEIMANE V., MITNICK D., MUKHERJEE JS., NUNN P., PASECHNIKOV A., TUPASI T., WELLS C., RAVIGLIONE MC. Multidrug-resistant tuberculosis management in resource-limited settings. Emerg. Infect. Dis., 2006, 12, 1389-97.

32 ORMEROD LP. Multidrug-resistant tuberculosis (MDR-TB): epidemiology, prevention and treatment. British Med. Bull., 2005, 73-74, 17-24. 
33 PABLOS-MENDEZ A., LESSNAU K. Clinical mismanagement and other factors producing antituberculosis drug-resistance. In: BASTIAN I., PORTALES F., Eds. Multidrug-resistant tuberculosis. Dordrecht, Netherlands: Kluwer Academic Publishers, 2000: 59-76.

34 PABLOS-MENDEZ A., RAVIGLIONE MC., LASZLO A., BINKIN N., RIEDER HL., BUSTREO F., COHN DL., LAMBREGTS-VAN WEEZENBEEK CS., KIM SJ., CHAULET P., NUNN P. Global surveillance for anti-tuberculosis drug-resistance, 1994-1997. World Health Organization/International Union Against Tuberculosis and Lung Disease Working Group on Anti-Tuberculosis Drug-resistance Surveillance. N. Engl. J. Med., 1998, 338, 1641-9.

35 PETRINI B., HOFFNER S. Drug-resistant and multidrug-resistant tubercle bacilli. Int. J. Antimicrob. Agents, 1999, 13, 93-7.

36 RAJBHANDARY SS., MARKS SM., BOCK NN. Cost of patients hospitalized for multidrug-resistant tuberculosis. Int. J. Tuberc. Lung Dis., 2004, 8, 1012-6.

37 RESCH SC., SALOMON JA., MURRAY M., WEINSTEIN M. Cost-effectiveness of treating multidrug-resistant tuberculosis. Plos. Med., 2006, 3, e24.

38 RUFFINO-NETO A. Tuberculosis: the neglected calamity. Rev. Soc. Bras. Med. Trop., 2002, 35, 51-8.

39 RULLÁN JV., HERRERA D., CANO R., MORENO V., GODOY P., PEIRÓ EF., CASTELL J., IBANEZ C., ORTEGA A., AGUDO LS., POZO F. Nosocomial transmission of multidrug-resistant Mycobacterium tuberculosis in Spain. Emerg. Infect.Dis., 1996, 2, 125-9.

40 SHAH NS., WRIGHT A., BAI GH., BARRERA L., BOULAHBAL F., MARTÍNCASABONA N., DROBNIEWSKI F., GILPIN C., HAVELKOVÁ M., LEPE R., LUMB R., METCHOCK B., PORTAELS F., RODRIGUES MF., RÜSCH-GERDES S., VAN DEUN A., VINCENT V., LASERSON K., WELLS C., CEGIELSKI JP. Worldwide emergence of extensively drug-resistant tuberculosis. Emerg. Infect. Dis., 2007, 13, 380-7.

41 SHARMA SK., MOHAN A. Scientific basis of directly observed treatment, shortcourse (DOTS). J. Indian. Med. Assoc., 2003, 101,157-8, 166.

42 SHARMA SK., MOHAN A. Multidrug-resistant tuberculosis. Indian J. Med. Res., 2004, 120, 354-76.

43 SHARMA SK., MOHAN A. Multidrug-resistant tuberculosis. A menace that threatens to destabilize tuberculosis control. Chest., 2006, 130, 261-72. 
44 SINGH UB., SURESH N., BHANU NV., ARORA J., PANT H., SINHA S., AGGARWAL RC., SINGH S., PANDE JN., SOLA C., RASTOGI N., SETH P. Predominant tuberculosis spoligotypes, Delhi, India. Emerg. Infect. Dis., 2004, 10, 1138-42.

45 SPELMMAN CW., MATTY KJ., WEISS SE. A survey of drug-resistant Mycobacterium tuberculosis and its relationship to HIV infection. Aids., 1998, 12,1915.

46 SUAREZ PG., FLOYD K., PORTOCARRERO., ALARCÓN E., RAPITI E., RAMOS G., BONILLA C., SABOGAL I., ARANDA I., DYE C., RAVIGLIONE M., ESPINAL MA. Feasibility and cost-effectiveness of standardised second-line drug treatment for chronic tuberculosis patients: a national cohort study in Peru. Lancet, 2002, 359, 1980-9.

47 TRAORE H., FISSETTE K., BASTIAN I., DEVLEESCHOUWER M., PORTAELS F. Detection of rifampicin resistance in Mycobacterium tuberculosis isolates from diverse countries by a commercial line probe assay as an initial indicator of multidrug resistance. Int. J. Tuberc. Lung Dis., 2000, 4, 481-9.

48 VALWAY SE., GREIFINGER RB., PAPANIA M., KILBURN JO., WOODLEY C., DIFERDINANDO GT., DOOLEY SW. Multidrug-resistant tuberculosis in the New York State prison system, 1990-91. J. Infect. Dis., 1994, 170, 151-6.

49 WILTON P., SMITH RD., COAST J., MILLAR M., KARCHER A. Directly observed treatment for multidrug-resistant tuberculosis: an economic evaluation in the United States of America and South Africa. Int. J. Tuberc. Lung Dis., 2001, 5, 1137-42.

50 WORLD HEALTH ORGANIZATION. Global Tuberculosis Programme. Treatment of tuberculosis: guidelines for national programmes. 2.ed. Geneva: WHO, 1997. [WHO/TB/97.220].

51 WORLD HEALTH ORGANIZATION. Anti-tuberculosis drug-resistance in the world: the WHO/IUATLD Global Project on Anti-tuberculosis Drug-resistance Surveillance. Geneva: WHO, 2000. [WHO/CDS/TB/2000.278].

52 WORLD HEALTH ORGANIZATION. The newsletter of the global partnership movement to Stop TB. Geneva: WHO, 2002d.

53 WORLD HEALTH ORGANIZATION. Guidelines for surveillance of drug-resistance in tuberculosis. Geneva: WHO, 2003. [WHO/CDS/TB/2004.343]. 
54 WORLD HEALTH ORGANIZATION. International Union Against Tuberculosis and Lung Disease. The WHO/IUATLD Global Project on Anti-Tuberculosis Drugresistance Surveillance 1999-2002: anti-tuberculosis drug-resistance in the world; third global report. Geneva: WHO, 2004.

55 WORLD HEALTH ORGANIZATION. Tuberculosis: the global burden: global TB fact sheet 2005. [serial online], 2005, [cited 2005 Dec. 25]. Available from: http://www.who.int/tb/publications/tb_global_facts_sep05_en.pdf.

56 WORLD HEALTH ORGANIZATION. Guidelines for the programmatic management of drug-resistant tuberculosis. Geneva: WHO, 2006. [WHO/HTM/TB/2006.361].

57 ZIGNOL M., HOSSEINI MS., WRIGHT A., WEEZENBEEK CL., NUNN P., WATT CJ., WILLIAMS BG., DYE C. Global incidence of multidrug-resistant tuberculosis. J. Infect. Dis., 2006, 194, 479-85. 